\title{
ANTIGUAS VECINDADES Y NUEVOS PROYECTOS EN EDIFICIOS PATRIMONIALES DE LA CIUDAD DE PUEBLA, MÉXICO
}

\author{
ANCIENT NEIGHBORHOOD AND NEW PROJECTS IN BUILDINGS \\ HERITAGE OF THE CITY OF PUEBLA, MEXICO
}

Enviado em 04 de setembro de 2015

Aceito em 20 de novembro de 2015

Juan Leonardo Ayala Rojas ${ }^{1}$

\begin{abstract}
Resumen: El estudio de las vecindades en los centros históricos es ante todo, una expresión al problema de la vivienda donde subyace el tema del patrimonio arquitectónico y su conservación, la cual busca a través de la ocupación para usos diferentes al habitacional garantizar su permanencia con un usufructo redituable. Por ello, el desalojo de antiguos inquilinos es frecuente, como lo es el cambio de uso de suelo y la transformación del partido arquitectónico original a partir de nuevas necesidades.

Se muestra en este trabajo, tres ejemplos de edificios de la época virreinal ubicados en la zona patrimonial de la ciudad de Puebla, que funcionaron como viviendas colectivas hacinadas y que fueron desalojadas, abandonadas durante algún tiempo, y ocupadas hoy por actividades distintas a la original. El primer caso, el bien inmueble es intervenido a través de la restauración de alto presupuesto. El segundo, una de las vecindades con mayor hacinamiento y antigüedad que se convierte en sede del gobierno estatal. El tercero hasta hace poco funcionó como vecindad, y donde se propone habilitarlo para hotel boutique. En todos los casos se pone el énfasis en su pasado como vecindad y el desalojo de sus habitantes.
\end{abstract}

Palabras-clave: Centro histórico de Puebla. Vecindades. Desalojos de edificios patrimoniales. México.

Abstract: The study of neighborhoods in historical city centers is first and foremost related to the problem of housing in architectural heritage areas. Heritage conservation efforts aim to shift usage of these properties away from residential use to other occupational methods to assure a stable source of revenue. In this process, the eviction of long-time residents is frequent. Also

\footnotetext{
${ }_{1}^{1}$ Arquiteto, professor da Faculdade de Arquitetura da Benemerita Universidad Autonoma de Puebla. E-mail: juanayala2000@yahoo.com.mx
} 
frequent are changes in land-use and transformation of architectural blueprints based on the new usage demands.

In this article three examples are examined of colonial-era buildings in the historical sector of the city of Puebla, Mexico. All three functioned as collective residences, whose residents were eventually evicted. The properties were abandoned for some time and are now occupied by activities different from those originally intended. In the first case, the intervention in the property was carried out through a high-cost restoration. The second case, one of the older properties with most past residents, was converted into a state government office. The third case, which until recently functioned as a collective residence, is now slated to become a boutique hotel. In all three cases the properties' past roles as residential buildings and the eviction of its long-time residents are emphasized.

Keywords: historical city center of Puebla, neighborhoods, eviction of architectural heritage buildings, Mexico.

\section{UNA CIUDAD CON HISTORIA}

El desarrollo propio de un centro urbano provoca a lo largo de su historia una serie de trasformaciones en el territorio, las cuales son resultado, entre otras cosas, de las políticas e instrumentos de desarrollo urbano que se aplican por parte de las autoridades encargadas de planificar el crecimiento de la ciudad o en la mayoría de los casos, de paliar los múltiples conflictos derivados de un desordenado metabolismo urbano. Una explicación de tal crecimiento se plantea como una expresión natural del aumento de la población, y de necesidades funcionales que tal incremento representa, por lo tanto las acciones gubernamentales deben estar encaminadas a regular la ocupación del espacio urbano ante la inevitable metropolización de los antiguos centros urbanos.

Una explicación más rigurosa debe considerar un espectro más amplio de circunstancias y agentes sociales que intervienen en la transformación del ambiente natural en ambiente construido y de ahí deslindar las causas y efectos de los múltiples intereses que despierta la ocupación del suelo urbano, y sobre todo las consecuencias sociales que tal ocupación acarrea. Los requerimientos del mercado inmobiliario, las demandas socio-espaciales de sectores específicos de la sociedad, la búsqueda de modernización urbana a través de las pautas establecidas por los organismos de gestión tanto estatal como municipal, son algunos de los componentes a considerar para una explicación más estricta. 
En el caso que nos ocupa se suma un aspecto relevante en cuanto al uso y desuso del espacio urbano-arquitectónico, ya que al estar analizando la compleja trama de una ciudad "histórica", es decir, una ciudad con más de cuatrocientos años de existencia y que cuenta con un acervo patrimonial importante tanto material como inmaterial: la ciudad de Puebla, México. Es comprensible entonces que la parte más antigua de ésta, conocida comúnmente como centro histórico, sea crisol de las diferentes concepciones e intereses sobre la función que debe tener una zona con altas posibilidades de atractivo cultural, turístico y sobre todo inmobiliario. La aplicación de determinados instrumentos reglamentarios y normativos en la zona histórica de la ciudad, y la relativa indiferencia hacia el problema social que palpita entre los muros de las viejas casonas virreinales dibuja una realidad que es materia de interés, ya que no se puede separar el estudio del patrimonio arquitectónico del considerando social.

Figura 1. Casa de alfeñique.

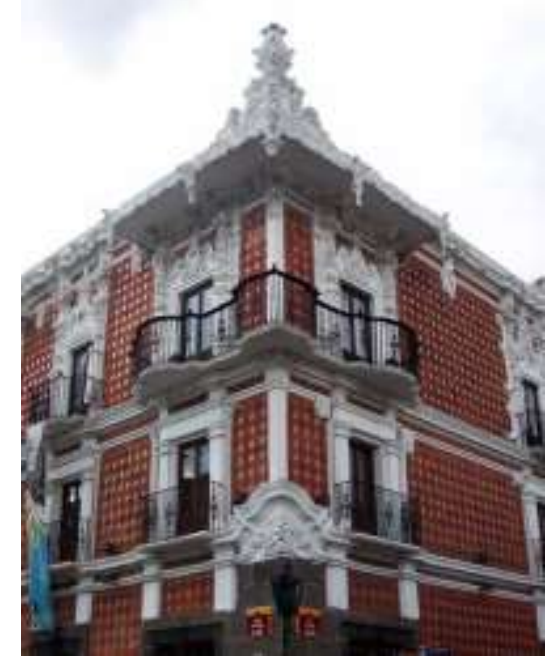

Fuente: Ismael Rangel Gómez. www.tripomatic.com

La ciudad de Puebla de Zaragoza fue fundada en 1531, exactamente diez años después de la caída de la gran Tenochtitlán y el inicio del período conocido tradicionalmente como virreinal en gran parte de la América hispanoparlante. Las tres centurias que duró esta etapa de la historia de México trajeron tres legados definitorios de la cultura mexicana. En primer lugar la castellanización en los hábitos primordiales de comunicación social tales como el lenguaje, la religión y la política. En segundo lugar el mestizaje tanto étnico como ideológico expresado en rituales que dieron origen a tradiciones y costumbres que aún subsisten. El tercero, una apropiación del espacio que, sobre todo en el caso de Puebla, suscitó un desarrollo extraordinario de la actividad constructora materializada en una arquitectura refinada y de elegante factura. Las construcciones que se levantaron sobre la traza original de la Puebla de los Ángeles, como fue su denominación inicial, y que conforman el llamado centro histórico, 
constituyen uno de los legados más importantes de la historia de la arquitectura a nivel internacional, razón por la cual fue declarada Patrimonio Cultural de la Humanidad en 1987 por la UNESCO.

A lo largo y ancho de la traza en damero se encuentran ejemplos sobresalientes de las diferentes fases estilísticas de la arquitectura de los siglos XVI al XIX expresadas en templos, conventos, colegios, edificios civiles, así como parques y paseos. En el momento cimero de su actividad económica y cultural (siglo XVIII), Puebla destacaba por la armonía y elegancia materializada en su arquitectura de corte barroco, churrigueresco o plateresco. La ciudad tenía un orden y signos de identidad muy claros que permitían sustentar una férrea convicción religiosa y confianza en los preceptos que imponía la corona española.

El ocaso del período virreinal y la posterior adaptación al régimen republicano modificaron radicalmente la cantidad y el tipo de construcciones que se levantaron en la ciudad. De hecho durante el siglo XIX ésta no rebasó sus límites originales y su función como centro político y religioso no se alteró, al igual que los barrios adyacentes, a los cuales se los tenía como dotadores de mano de obra. Una primera transformación en la conformación de la ciudad sucede durante el período conocido como Porfiriato, finales del siglo XIX y principios del XX, el cual auspició la llegada de los símbolos del "progreso" a través de una arquitectura de corte europeo y servicios urbanos modernos. Período de bonanza en lo constructivo, que adopta los modelos de corte neoclásico y art nouveau entre otros, así como trabajos de ampliación o adaptación de muchos edificios del período virreinal. El incremento de la población trajo nuevas condiciones de funcionamiento entre las cuales destaca la ocupación de los inmuebles y la redistribución de la población en nuevos sitios (fuera del casco principal). Esta fase de desarrollo urbano en Puebla se interrumpe debido a la revolución mexicana, que si bien mantuvo sin alteraciones la parte consolidada de la ciudad, no lo hizo en lo poblacional, ya que nuevos habitantes de otras regiones, o los habitantes de los barrios adyacentes empiezan a buscar acomodo en el casco central de la ciudad.

Una vez superados los estragos del movimiento armado en México, la ciudad de Puebla inicia un proceso de expansión que no se ha detenido hasta nuestros días. Nuevos modelos de expansión física que incentivan la lotificación y comercialización de lotes, alteran el perfil urbano con la aparición de colonias (o barrios) y nueva arquitectura, dándose en el centro histórico un proceso de pauperización gradual que tiene su expresión más simbólica en los edificios que ahora son ocupados como vivienda colectiva y que se conoce convencionalmente como vecindades. La ocupación de antiguas y grandes viviendas señoriales por un gran número de familias ha representado a lo largo de los años una forma de cultura popular no exenta de valores y conflictos, 
sobre todo cuando se toma como muestra del problema de vivienda encarnado en el uso y desuso del patrimonio arquitectónico de la ciudad.

\section{CONCEPTO DE VECINDAD}

La definición de vecindad que se obtiene del diccionario de la real academia española, refiere a un conjunto de personas que viven en cercanía ocupando una casa o varias inmediatas las unas de las otras (Real Academia Española, 2001). La cualidad de vecino es el punto de descripción pero omite el aspecto de la apropiación del espacio arquitectónico y las condiciones de vida tradicionales, usos y adecuaciones de ese espacio, relaciones de convivencia, costumbres y otras prácticas sociales que en conjunto moldean una vertiente de la cultura urbana. Por esta razón es necesario exponer el concepto de vecindades del cual se parte, para tener una comprensión más clara del problema social que subyace en la zona histórica de la ciudad de Puebla. ${ }^{2}$

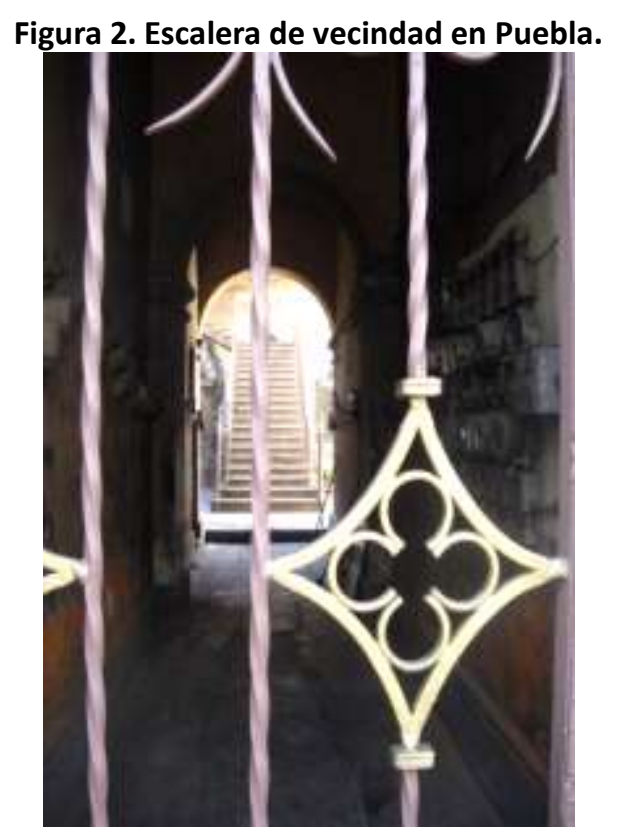

Fuente: Juan L. Ayala Rojas

Cuando se hace referencia a una vecindad se está pensando en aquellos monumentos del período virreinal que son ocupados como vivienda colectiva en deficientes condiciones de higiene y servicios, lo que acarrea un deterioro paulatino de los inmuebles considerados patrimonio. La inadecuación de estos soportes materiales para actividades no concebidas en el momento de su construcción, conlleva situaciones de hacinamiento e insalubridad. Pero, a pesar de ello, se encuentra un tejido de

\footnotetext{
2 No solo en Puebla subsiste este problema. De hecho en todas las ciudades virreinales de la república mexicana encontramos la misma situación, siendo la ciudad de México la de más fuerte conflicto social.
} 
relaciones sociales que dan a las vecindades una identidad específica y muy diferente a las que pueden generarse en otros tipos de vivienda colectiva (unidades habitacionales o conjuntos de vivienda). De esta forma han sobrevivido varias generaciones de ocupantes, por lo tanto, cualquier intervención debe considerar los efectos que producirá a los inquilinos tal o cual medida impulsada para el rescate de los centros históricos.

Dentro de la problemática general que representa el centro histórico de la ciudad de Puebla, el tema de la vivienda es quizá el más álgido por las razones antes expuestas. Generalmente la preocupación de los actores que intervienen en la llamada zona de monumentos remite exclusivamente a consideraciones estéticas y apologéticas del arte virreinal representadas en la arquitectura con un afán turístico y escenográfico que permita usufructuar la mencionada zona a través de trabajos técnico constructivos de remozamiento. Se pasa por alto la diversificación de actividades que se realizan en el centro histórico (comercio, administración, educación, vivienda etc.) y por lo cual, toda política que se implemente afectará la red de intereses que subyacen en dicha zona. La presencia de intereses completamente antagónicos (inquilinos/propietarios) así como la necesidad del capital inmobiliario por elevar la renta del suelo, perfilan un problema que no puede darse sobre la base de una propuesta técnica únicamente.

El desarrollo de las vecindades en la ciudad de Puebla parte de un momento en el que la aparición de nuevos actores sociales influye en la conformación del espacio urbano, los promotores inmobiliarios, quienes producen nuevos asentamientos con condiciones de mayor confort y servicios. Se puede ubicar temporalmente este proceso a partir del primer tercio del siglo XX, momento en que la burguesía poblana se muda hacia nuevos fraccionamientos ubicados en la periferia pero con mejores servicios. El desuso de grandes obras palaciegas se convierte en la vivienda para una población pobre que acepta vivir sin servicios y en espacios concebidos para otra actividad. La condición socioeconómica de estos nuevos habitantes impide su acceso a otro tipo de vivienda, por lo que la ocupación y habilitación de estos inmuebles se realiza de manera muy precaria. Vélez Pliego apunta lo siguiente:

En los hechos, el funcionamiento del mercado inmobiliario en Puebla va a presionar hacia la permanencia, en la Zona de Monumentos, de segmentos de población que no pueden ser sujetos de crédito dentro de los esquemas de financiamiento subsidiado; o de población que sea beneficiaria por asignación de la vivienda producida por los promotores públicos (VÉLEZ, 2007, p. 124).

A lo largo de la historia de las vecindades poblanas, se conforma una especie de subcultura urbana que tuvo manifestaciones sociales que han sido retomadas $y$ referenciadas a través de expresiones que pasan por la literatura, dramaturgia o 
cinematografía, y que retratan un estilo particular de vida donde los valores, costumbres, tradiciones, el lenguaje, referencias ideológicas como la religión, son sublimadas en aras de un reconocimiento social hacia este sector de la población.

Dentro de una connotación muy mexicana, las vecindades y sus ocupantes sirven de referencia para entender parte de nuestra idiosincrasia.

\section{LAS VECINDADES COMO TEMA DE ESTUDIO}

El estudio sobre las vecindades del centro histórico de la ciudad de Puebla ha tenido diversos exponentes, destaca la investigación antropológica realizada a mediados de los setenta por el antropólogo Enrique Marroquín (1983) que lleva por nombre "Las vecindades de Puebla", quién sobre un estudio de caso determina la problemática inherente a estos edificios y sus habitantes en cuanto a estilo de vida, las condiciones socioeconómicas, el estado de sus viviendas y la política urbana encaminada al cambio de usos del suelo (Marroquín, 1985). Un estudio más durante los ochenta, es el que realiza el Departamento de Investigaciones en Arquitectura y Urbanismo (DIAU) de la Universidad Autónoma de Puebla y que pretendía una política de "recuperación" para estos inmuebles y sus inquilinos, que implicaba "conciliar los soportes materiales del pasado con las relaciones sociales que ahora se desarrollan" (PATIÑO, 1983).

Destaca el libro "El pasado en el presente: pobreza, centro histórico y ciudad (2002) de Elsa Patiño Tovar, quien desde la óptica de las ciencias sociales aborda el proceso de degradación y pauperización de la zona patrimonial y las condiciones de los habitantes de la misma. El tema de las vecindades es el eje alrededor del cual se explica y confronta la postura sobre la salvaguarda del patrimonio como un mero recurso discursivo.

Finalmente en un plano más descriptivo y coloquial, el catedrático y conferencista Rodolfo Pacheco Pulido publica el libro "Vecindades de Puebla", texto que da cuenta de anécdotas e historias originadas en los patios, habitaciones, azoteas y muros de añeja construcción.

Si un elemento es constante en la literatura sobre las vecindades es la amenaza del desalojo. A partir de la declaratoria de la zona de monumentos históricos, y más tarde Patrimonio Cultural de la Humanidad de su centro histórico, el interés y pretensiones sobre los inmuebles que contiene se incrementaron a través de programas y políticas de reivindicación-revitalización que suscitaron una constante amenaza contra los avecindados del lugar. Marroquín apunta que a partir de 1978 la frecuencia de desalojos se incrementó y algunos de los motivos que ponían en riesgo la permanencia de los inquilinos eran la venta del inmueble ante la carencia de recursos para su 
mantenimiento, búsqueda de mayor ganancia para los propietarios, implicaba el aumento de rentas, demolición de la casa por su deterioro, embellecimiento de la parte central de la ciudad, y la intención de mejorar la clase de inquilinos en la zona (MARROQUÍN, 1985, p. 233).

A partir de la década de los noventa ha sido notorio el proceso de sustitución de usos del suelo en gran parte de la zona patrimonial, encaminada al aprovechamiento del mercado inmobiliario. Las adecuaciones funcionales en muchos de los edificios patrimoniales han sido motivo de polémica constante entre los defensores del patrimonio, posibles inversionistas, autoridades municipales y estatales, y a manera de mero espectador, los habitantes de la zona. Ha sido evidente la disminución de los residentes como resultado del nuevo papel que el mercado inmobiliario le ha asignado a esta zona, y que en materia de vivienda va dirigido a los sectores de altos ingresos. La vivienda colectiva que compartía servicios, espacios, de costumbres arraigadas y cultura propia no tiene cabida en esta nueva etapa del centro histórico poblano.

\section{CASOS DE ESTUDIO}

En 2007, a veinte años de la inscripción de la ciudad como patrimonio cultural de la humanidad, el cuerpo académico de Estudios Arquitectónicos de la facultad de Arquitectura de la BUAP se dio a la tarea de revisar el estado de algunas antiguas vecindades visitadas y encuestadas en su momento para obtener elementos de análisis de las políticas y programas aplicadas al centro histórico en este lapso de tiempo. Inmuebles todos ellos patrimoniales y con diferentes grados de deterioro. Lo encontrado se publicó con el nombre de Vecindades del centro histórico de la ciudad de Puebla veinte años después (AYALA; FERNÁNDEZ, 2010). Sobre la base de este trabajo se presentan tres ejemplos de antiguas vecindades que ahora son ocupadas o propuestas para otras actividades.

\section{PRIMER EJEMPLO: LA TOCINERÍA}

El aspecto actual de este viejo inmueble del siglo XVII ubicado en la calle 2 sur número 904, muy cerca del zócalo citadino, dista mucho de cuando albergó hasta diez familias a mediados de los ochenta. Es una construcción de dos niveles compuesta de tres balcones de piedra laja y balcones de herrería en la parte alta, dos de ellos de austera desnudez que flanquean un tercero más alto y más ancho. El acceso original se había modificado haciéndolo más estrecho. En la planta baja, flanqueando la entrada principal, contaba con algunas accesorias utilizadas como comercios. El interior modificado, no 
permitía reconocer las arcadas ni el patio central. En la parte posterior se encuentra una enorme nave con una arcada central que sostenía una techumbre de madera ya inexistente. Una placa colocada recientemente a la entrada del edificio reza que durante el período virreinal fue lugar donde la industria de jamones y tocinos se desarrolló. De ahí su nombre La Tocinería.

Figura 3. Casa 2 sur 904 en 1984.

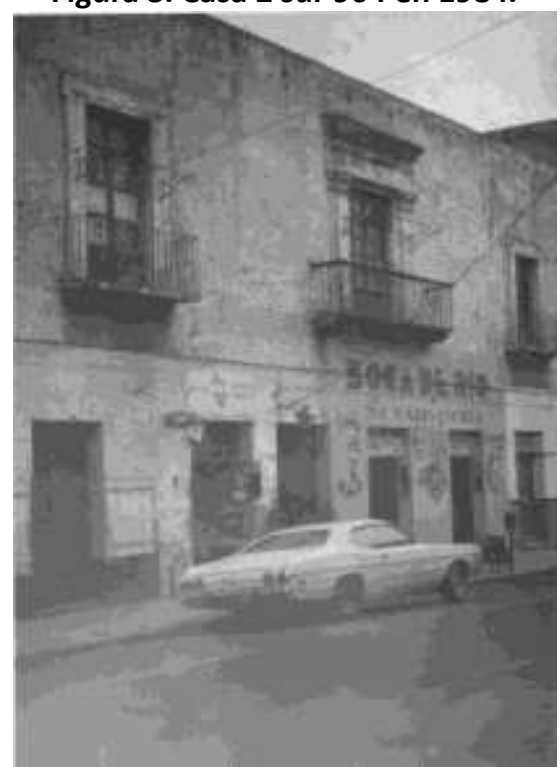

Fuente: Juan L. Ayala Rojas

Del trabajo realizado en 1984 se supo que pertenecía a la Beneficencia Pública. Albergaba ocho familias, la mayoría habitaba de una a tres piezas. A mediado de los años 50 el número de familias llegó a ser veinte, hasta que los primeros derrumbes de techos dejó inservibles varias habitaciones por lo que muchas familias se fueron yendo. El éxodo fue poco a poco, y las últimas tres familias fueron desalojadas mediando una gratificación económica. El estado del inmueble era deplorable, aunque se hicieron reparaciones leves cuando fue necesario. De la entrevista al inquilino más antiguo de la vecindad (más de treinta años viviendo ahí) se toma conocimiento sobre los problemas cotidianos que enfrentaban.

'Aquí el problema más grande es el del baño-nos comentóagua sí cae pero sólo hay dos baños, uno arriba y otro abajo... y cuando llegan los tiempos de lluvia los techos derrumban....en la parte alta hay varios cuartos vacíos pero no se pueden ocupar pues no tienen techo'. El inconveniente más agudo se presentó cuando una cañería se tapó y durante meses los deshechos de los dos únicos baños que servían en todo la vecindad se acumularon. 'Hay que comer escalonado-se quejósi no, todos quieren ir al baño a la misma hora'.

A finales de los noventa estaba vacía, fue adquirida por un particular que la ha venido restaurando con un nuevo uso, la recuperación se inicia en 2002. Estudios 
históricos apuntan que el nombre original del inmueble fue Antiguo Trato de Tocinería, lo conformaba la casa, algunas accesorias y un área destinada al obraje, al paso de los siglos la propiedad se subdivide. Se intervino el interior respetando la distribución original, estableciendo registros que documentan la estructura del inmueble, sistemas constructivos y materiales existentes, retirando elementos no originales. Los trabajos de restauración, consolidación y adecuación tardaron alrededor de once años, y se continúan hasta la fecha para concluir con el proyecto de adaptación museográfica. Hoy día es un referente de interés turístico y fuente documental de la historia de la ciudad. Actualmente es utilizada para fines socio-culturales.

Figura 4. Antiguo Trato de Tocinería en 2009.

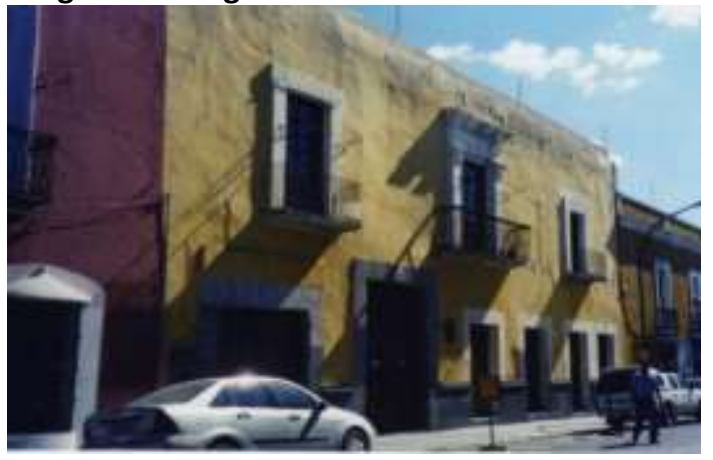

Fuente: Juan L. Ayala Rojas

Figura 5. Vista Interiores restaurados.

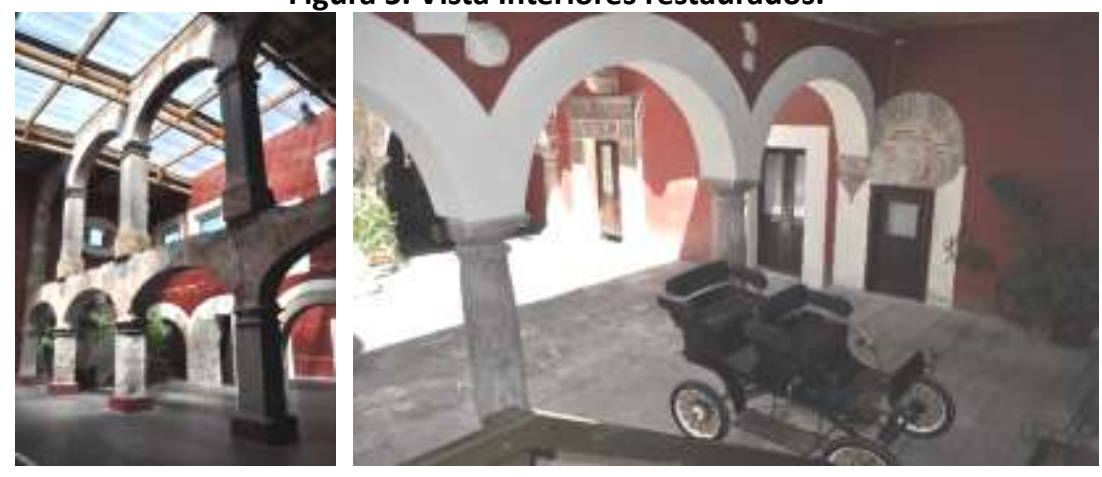

Fuente: Colección particular Alejandra Ortega Cambranis

\section{SEGUNDO EJEMPLO: CASA DE LA AGUAYO}

El barrio de El Alto en la ciudad de Puebla es uno de los más antiguos y de mayor tradición. Pertenece a la zona de la fundación original de la ciudad. Durante años fue un lugar descuidado con construcciones antiguas y deterioradas por la falta de mantenimiento, habitadas por los sectores más populares de la población. Esta situación se mantuvo hasta que a principios de los años noventa se realizaron trabajos de 
remozamiento y su aspecto se transformó. Visitamos este añejo lugar a mediados de los años ochenta una enorme construcción del siglo XVII ubicada sobre la calle 14 oriente, antiguamente conocida como calle Real del Alto, signada con el número 1204.

Figura 6. Casa de la Aguayo en 1984

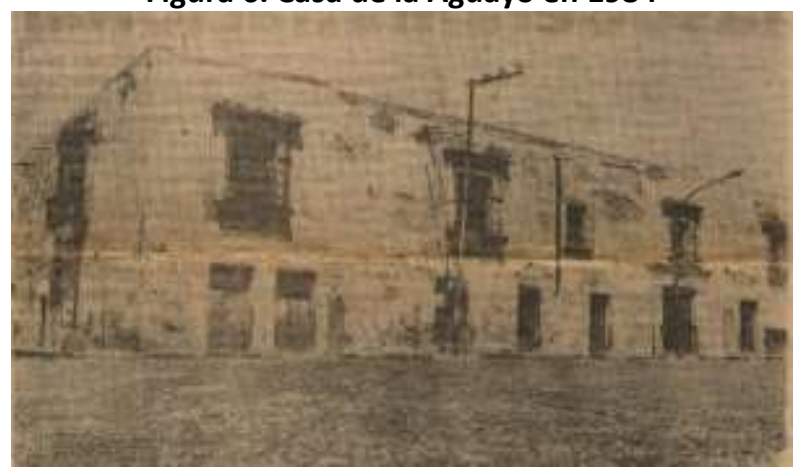

Fuente: Juan L. Ayala Rojas

Una fachada imponente, austera, y destacando cuatro balcones de hierro forjado, algunas accesorias y un portón adintelado era la carta de presentación de una de las vecindades más grandes y hacinadas del barrio, albergaba alrededor de treinta familias. Impresionaba el hacinamiento y condiciones sanitarias de las viviendas, estas se agolpaban alrededor de un gran patio central que se subdividió para levantar pequeñas habitaciones. El lugar daba un aspecto laberíntico.

Eran momentos tensos los que vivían los inquilinos en esa ocasión, habían recibido la orden de desalojo por parte de las autoridades militares, ya que el inmueble pertenecía a la veinticincoava zona militar. Algunos de éstos eran soldados pensionados o descendientes de los mismos por lo que sentían como suya la propiedad. La mayoría de los inquilinos no pagaban renta y sólo cooperaban con una suma modesta para su mantenimiento. La incertidumbre permeaba el ambiente entre las familias que no tenían condiciones para mudarse a pesar de tener un plazo de tres meses para retirarse. Las quejas eran lugar común en las entrevistas:

Hemos intentado llegar a un acuerdo- nos comentó un inquilino- pero en la 25 ava zona nos dijeron que no podían hacer nada y que llegando el momento tendremos que desalojar... que si no nos íbamos mandarían soldados para sacarnos pues el plazo no se iba a prorrogar.

Un grupo reducido trató de poner resistencia al desalojo, se organizaron y buscaron evitarlo por la vía legal, pero fue inútil. Finalmente la visita de un contingente de soldados obligó a los inquilinos a firmar de conformidad su salida por lo que en menos de seis meses el inmueble quedó vacío.

Esta construcción es conocida como Casa de la Aguayo por haber vivido en ella Micaela Pérez de Aguayo. A lo largo de su historia albergó comercios, bodegas, baños 
públicos y a principio del siglo XX pasó a formar parte del patrimonio del ejército. Como vecindad sirvió durante sesenta años.

Durante la década de los noventa se hicieron trabajos de rehabilitación en el inmueble y pronto se convirtió en la sede del gobierno estatal.

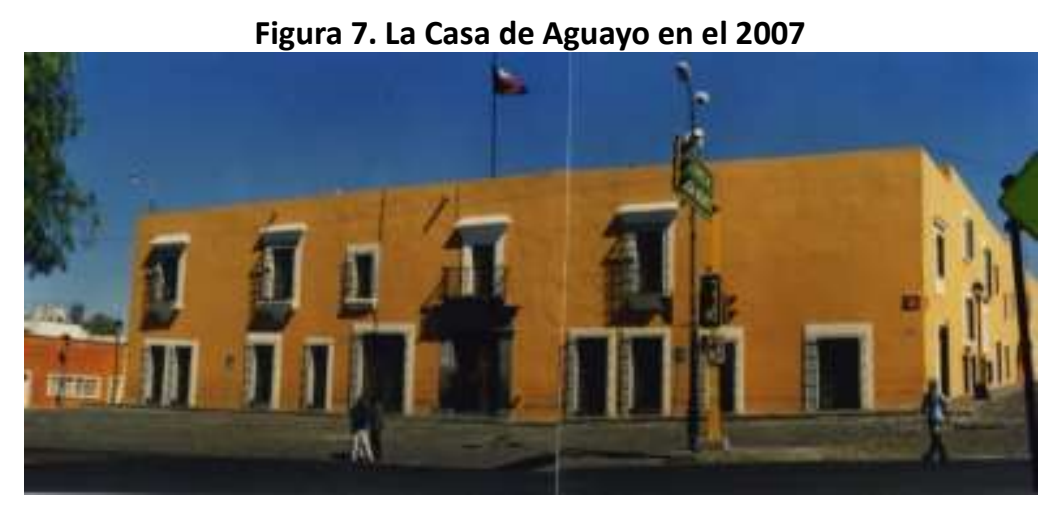

Fuente: Juan L. Ayala Rojas

A la par, se han hecho trabajos de remozamiento en el barrio de El Alto propiciando una fuerte inversión del sector inmobiliario que ha modificado su aspecto y su uso del suelo.

\section{TERCER EJEMPLO: HOTEL BOUTIQUE LA TROJE (PROPUESTA)}

El inmueble que se presenta fue vecindad hasta hace poco tiempo (diciembre 2013). Ubicada en la calle 13 poniente, antiguamente Calle de los Gozos, número 107, fue habitada por numerosas familias a lo largo de cuarenta años. A mediados de los años noventa el número de habitantes empezó a disminuir ante el peligro que representaban los constantes derrumbes y el desgaste propio de una construcción que no se le da mantenimiento. Fue tomada como tema de tesis de licenciatura en arquitectura proponiendo su restauración para un hotel boutique dadas sus características estéticas y compositivas. ${ }^{3}$ El tema de los inquilinos no se aborda en dicho estudio razón por la cual se lo quiere analizar en este trabajo.

Una breve descripción del inmueble, refiere que se trata de una construcción del siglo XIX con agregados del XX, el exterior conserva el aspecto casi original. Presenta en su fachada una composición simétrica en los dos niveles. En planta baja destaca el vano de acceso, cuatro vanos más, un guardapolvo, jambas, dintel con clave resaltada mostrando el número original en bajo relieve, todo en cantería. Los vanos de ventana

\footnotetext{
3 Esta parte del trabajo toma como base un ejercicio de investigación realizado por los estudiantes de arquitectura Ricardo Chico, Rogelio Méndez, Hugo Sánchez y Antonio Trinidad para acreditar la asignatura Metodología de Investigación (ARQM-270). Restauración del inmueble caso 13 ponientes \#107. Equipo MTD-3/04. Verano de 2013.
} 
presentan las mismas características, con protecciones de hierro forjado y emplomados y sólo uno de madera.

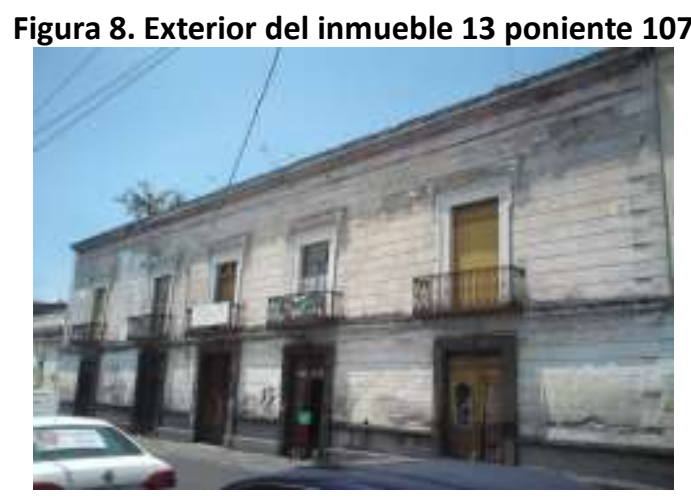

Fuente: Equipo MTD-03/4

A lo largo de toda la fachada corre una cornisa que separa los dos niveles. En planta alta destacan cinco vanos con enmarcamiento moldurado con acodos en argamasa y una cornisa; todos con balcón. El macizo de la fachada presenta un acanalamiento horizontal en su aplanado con friso liso.

El partido interior presenta la clásica distribución de la casa poblana. Un zaguán que da acceso a un primer patio amplio con una escalera a tres rampas que lleva al segundo piso. Una serie de crujías alrededor de este. En el extremo oriente un pasillo que lleva al segundo patio con una fuente y dos escaleras más. Se repite el modelo de las crujías. Los muros son de grueso espesor y sostenían techumbres de vigas de madera y tejamanil. Los pasillos del primer patio a base de arco de tres puntos y los del segundo de cubierta catalana.

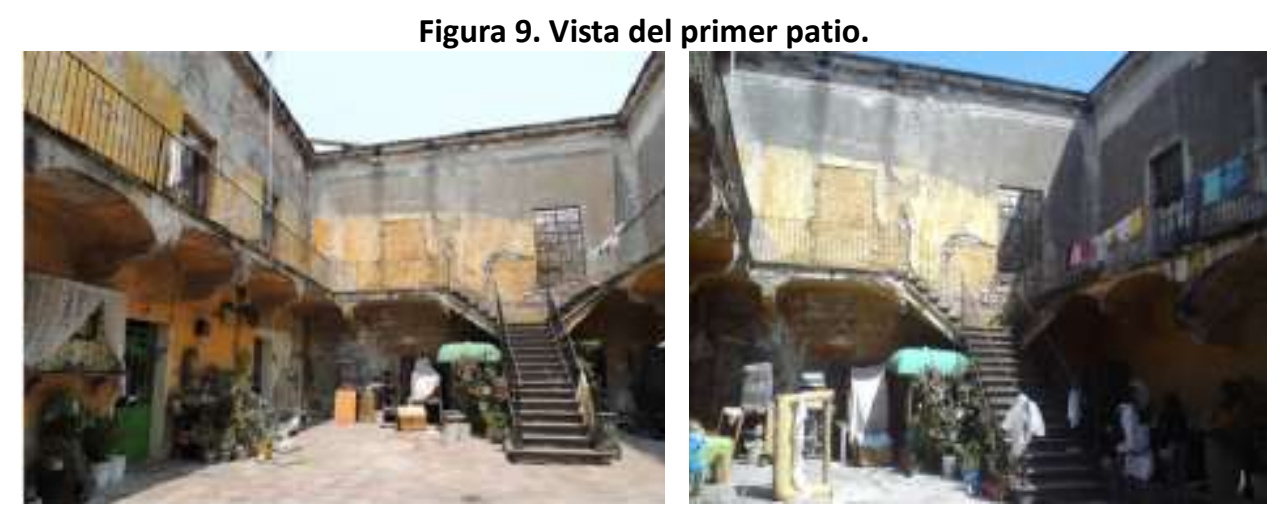

Fuente: equipo MTD-03/4 1

El lugar donde se ubica el inmueble es de alto valor comercial debido a su cercanía con puntos de interés turístico y de servicios en el centro histórico. Se encuentra en la misma calle el templo de Nuestra Señora de los Gozos, construida en el siglo XVIII que muestra escenas de los siete gozos de María en la fachada. Además la zona cuenta con numerosas muestras de la arquitectura histórica de Puebla. Uno de ellos el Templo 
del Carmen y su parque a sólo dos cuadras de nuestro ejemplo. Es un punto turístico importante por lo que la propuesta de hotel para este edificio parece rentable.

En relación al desalojo, el estudio del inmueble permitió entrevistar a los últimos ocupantes. En ese momento se trataba de dos familias, una de ellas tenía menos de diez años ocupando dos cuartos del segundo patio donde el padre de familia había acondicionado un pequeño taller. No contaban con servicios sanitarios y la humedad del lugar ponía en peligro su permanencia en el inmueble. Se encontraban ahí debido a que no pagaban renta por acuerdo con el actual propietario siempre que realizaran pequeños trabajos de conservación. La otra familia estaba compuesta por una señora de edad avanzada quien era la encargada del lugar y vivía junto con su hija en las habitaciones que dan a la calle donde habían acondicionado una pequeña tienda entre la reja de una accesoria. A través de esta entrevistada se pudo contactar a una de las familias más antiguas de la vecindad quienes habían abandonado el lugar cuando la techumbre de su casa se desplomó. De las anécdotas y recuerdos se pudo conocer los antecedentes del abandono de la vecindad. El mismo se produjo durante la década de 1940 cuando la casona empezó a utilizarse como vivienda colectiva y llegaron familias provenientes del campo que rentaban de dos a tres cuartos. No obstante que los servicios eran comunitarios poco a poco los inquilinos adecuaron a sus propias necesidades el lugar, construyendo un par de retretes en el segundo patio y agregando algunos espacios para extender las habitaciones. Los dueños cobraban una cantidad mínima por cuarto y las reparaciones las descontaban de la renta. Así fue durante un par de décadas, la vecindad llegó a contar con más de quince familias. La integrante de mayor edad en la citada familia contaba con más de setenta años, relata que ella había nacido ahí, celebró sus quince años en el patio de la casona, se casó y formó su familia en la misma vecindad, ocupando un departamento con servicios en la parte superior del primer patio.

El cobro de la renta era realizado por la propia dueña del edificio y los aumentos eran mínimos hasta el punto de congelarse a finales de los setenta. A principios de los ochenta se anuncia que el inmueble se vendería, por lo que el desalojo era necesario. Advirtió que se seguiría cobrando la renta pero que los arreglos del edificio ya no iban a descontarse de ésta y correrían por cuenta de los ocupantes. Esto propició un paulatino deterioro de los techos primero y poco a poco del resto de la estructura, lo que llevó a un gradual abandono de la vecindad. Los usos de algunos cuartos de la planta baja cambiaron convirtiéndose en bodegas de muchos comerciantes ambulantes que se habían asentado en el primer cuadro de la ciudad. La vida cotidiana de la vecindad se hizo más tortuosa pues desaparecía el uso habitacional no solo del inmueble sino de la zona en su conjunto. La calle adquirió un uso comercial por lo que el destino del inmueble era predecible y el éxodo de vecinos se incrementó. La aplicación del proyecto 
urbano del Paseo del rio de San Francisco impulsado por el gobierno estatal a mediados de los años noventa tuvo repercusiones sobre todo el centro histórico de la ciudad de Puebla en la búsqueda de mayor rentabilidad del suelo. Ante la inexistencia de líneas de crédito para vivienda en la zona monumental, las viviendas en renta han sido abandonadas paulatinamente por lo grupos sociales de menores ingresos (VÉLEZ, 2007, p. 182).

\section{CONCLUSIONES}

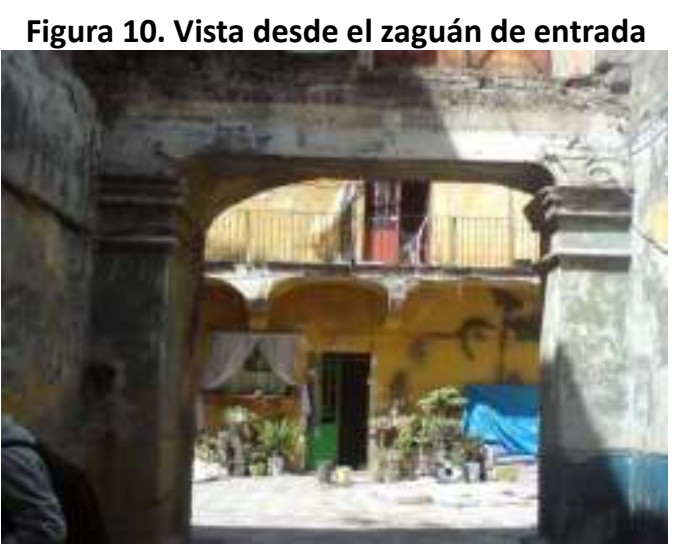

Fuente: equipo MTD-03/4

Las condiciones de las vecindades en el centro histórico de la ciudad de Puebla continua siendo la misma, falta de apoyo para su rehabilitación sin importar que sean edificios históricos. Las políticas adoptadas por el gobierno municipal son de amenaza tal como se puede apreciar en las notas periodísticas como la que se anexa:

\section{"ATIENDEN REHABILITACIÓN.}

Tras la advertencia del INAH, propietarios de 60 casonas ubicadas en el Centro Histórico han comenzado trabajos de mantenimiento para impedir la expropiación" Pérez, Pilar (2014, septiembre 21) Atienden rehabilitación. El Sol de Puebla, sección local, primera plana.

La nota se refiere al ultimátum a los dueños de 150 inmuebles para que realicen labores de mantenimiento de las casonas y evitar así el riesgo de colapso y su posible expropiación. Se recomienda que de no contar con los recursos suficientes los propietarios pueden asociarse con particulares para realizar el proyecto o en el último de los casos que vendan la propiedad. En entrevista el perito del INAH Sergio Vergara Berdejo expresó que alrededor del $40 \%$ de las casas emplazadas han empezado a ser reparadas y que en un año serán visibles los resultados de las intervenciones. De hecho 
la amenaza de expropiación ha dado resultados pues según la nota un número considerable de casonas han sido compradas por la iniciativa privada (no precisa números). Es evidente entonces que la política de intervención en el centro histórico va encaminada a fortalecer el capital privado en materia inmobiliaria y la oferta de suelo para uso comercial o de vivienda media en el área refuerza la expulsión de los antiguos pobladores. La aplicación de una política que evite la degradación de los inmuebles por esta vía, en palabras de Patiño:

...hace patente el encuentro de dos premisas: la carrera por la revaloración del suelo urbano que provoca la expulsión de las actividades menos rentables, como lo es la vivienda para sectores de bajos ingresos... y la práctica que aspira a reconocer solamente aquellas construcciones como símbolos; lo cual no sería cuestionable si no fuera porque excluye la posibilidad de instituirlo como soporte para la creatividad de los sectores de bajos recursos que ahí habitan (PATIÑO, 2002, p. 3).

\section{REFERENCIAS}

ÁlVAREZ Mora, A. El Mito del centro histórico. México: UIA/ BUAP/Universidad de Valladolid, 2006.

AYALA ROJAS, Juan L. ; FERNÁNDEZ DE LARA A, Carmina. Vecindades del centro histórico de la ciudad de Puebla: veinte años después. In: El patrimonio edificado en Puebla a veinte años de su inscripción como patrimonio mundial. México: Benemérita Universidad Autónoma de Puebla, 2009.

BÜHLER, Dirk. Puebla: patrimonio de arquitectura civil del virreinato. Alemania: Deutsches Museum/ICOMOS, 2001.

GOBIERNO del Estado de Puebla. Catálogo de monumentos arquitectónico, artísticos e históricos de la Ciudad de Puebla. Puebla, 1985.

LEICHT, Hugo. Las calles de Puebla. Puebla: Junta de Mejoramiento, Cívico y Material del Municipio de Puebla, 1986.

MARROQUÍN, Enrique, et al. Lenguaje, ideología y clases sociales. Las vecindades de Puebla. México: Universidad Autónoma de Puebla, 1985.

PACHECO PULIDO, Rodolfo. Vecindades de Puebla. Puebla: Gobierno del Estado de Puebla, 2001. 
PATIÑO TOVAR, Elsa. La vivienda popular en el centro histórico de la ciudad de Puebla.

[Puebla], 1987. Proyecto de Investigación presentado al CONACYT. Documento mimeografiado.

PATIÑO TOVAR, Elsa. El pasado en el presente: pobreza, centro histórico y ciudad. Puebla:

Benemérita Universidad Autónoma de Puebla, 2002.

PROPUESTA de restauración del inmueble caso 13 poniente \#107, centro histórico: trabajo de investigación presentado para acreditar la materia de Metodología de la Investigación. Equipo MTD-03/4. [Puebla]: Benemérita Universidad Autónoma de Puebla, 2013. 